Acta Cryst. (2002). A58 (Supplement), C178

\section{INCOMMENSURATE MODULATIONS IN THE STRUCTURE} OF Bi-III

M. I. McMahon ${ }^{1}$ O. Degtyareva ${ }^{1}$ R.J. Nelmes ${ }^{1}$ L. Palatinus ${ }^{2}$ S. van Smaalen ${ }^{2}$ ${ }^{1}$ The University of Edinburgh Department of Physics and Astronomy Kings Buildings Mayfield Road EDINBURGH MIDLOTHIAN EH9 3JZ UK ${ }^{2}$ Laboratory of Crystallography, University of Bayreuth, D-95440 Bayreuth, Germany

The crystal structure of Bi-III, stable between 2.8 and $7 \mathrm{GPa}$, has long been known to be complex and has attracted much attention. Although previously described as orthorhombic or tetragonal, we have recently shown [1] that Bi-III is in fact incommensurate, comprising a body-centred tetragonal (bct) 'host' and a bct 'guest' component made up of chains that lie in channels in the host; the guest is incommensurate with the host along the tetragonal c-axis.

In our powder-diffraction patterns of Bi-III, we identified two additional very weak peaks that we speculated may arise from a further modulation of the host or guest structures [1]. To confirm the origin of these satellite peaks, we have performed a single-crystal study of $\mathrm{Bi}$-III at $4.5 \mathrm{GPa}$ in which more than 200 of these satellite reflections were located and their intensity measured. Using the satellite reflections, it has been possible to perform a full 4-dimensional refinement of the Bi-III crystal structure, and thereby model the modulations of the host and guest structures. The full Bi-III structure will be presented. References

[1] M.I. McMahon, O. Degtyareva and R.J. Nelmes, Phys. Rev. Lett. 85, 4896 (2000).

\section{Keywords: HIGH PRESSURE CRYSTAL STRUCTURES} INCOMMENSURATE
Acta Cryst. (2002). A58 (Supplement), C178

COMPLEX METAL STRUCTURES AT HIGH PRESSURES

R. J. Nelmes M. I. McMahon O. Degtyareva T. Bovornratanaraks C. Hejny1 S. Rekhi D. R. Allan J. S. Loveday S. A. Belmonte

Affiliations:

Department of Physics and Astronomy and Centre for Science at Extreme Conditions, The University of Edinburgh, Edinburgh EH9 3JZ, UK

We have recently found many new complex structures in $\mathrm{Rb}, \mathrm{Cs}, \mathrm{Sr}, \mathrm{Ba}, \mathrm{Ga}$, $\mathrm{As}, \mathrm{Sb}, \mathrm{Bi}$ and other metallic elements. In some cases, these structures comprise two interpenetrating components - one a 'host' framework and the other a 'guest' structure made up of chains that occupy channels in the host that are incommensurate with each other. In the group V elements, these components are not only incommensurate with each other but also are modulated, giving rise to additional satellite reflections. In other cases, the complexity is expressed as a superstructure of a simpler structure. And in yet other cases, there is a complex stacking of different layers - which may be understood as another form of modulation. In this presentation, we will present an overview and explore key aspects of the emerging systematics of these remarkable new structures, some of which have of the order of 100 atoms in the unit cell.

\section{Keywords: HIGH PRESSURE CRYSTAL STRUCTURES PHASE TRANSITIONS}

\section{Acta Cryst. (2002). A58 (Supplement), C178 \\ PRESSURE-INDUCED AMORPHOUS-AMORPHOUS TRANSITION IN MOLECULAR SOLID SnI}

A. Ohmura ${ }^{1}$ K. Sato ${ }^{2}$ H. Yamazaki ${ }^{1}$ N. Hamaya ${ }^{1}$ M. Isshiki ${ }^{3}$ Y. Ohishi ${ }^{3}$

$\mathrm{O}^{1}$ chanomizu University Graduate School of Humanities and Sciences 2-1-1 Otsuka, Bunkyo-Ku TOKYO 112-8610 JAPAN ${ }^{2}$ JST ${ }^{3}$ JASRI

A metallic amorphous form of $\mathrm{SnI}_{4}$ is induced by compression above $15 \mathrm{GPa}$ at room temperature. Our recent study showed that the $\mathrm{SnI}_{4}$ molecules no longer existed above $35 \mathrm{GPa}$ in the amorphous state and that measured diffraction profiles exhibited many features of the amorphous structure formed by the dense random packing of hard spheres (DRPHS). Above $61 \mathrm{GPa}$, amorphous $\mathrm{SnI}_{4}$ transforms to a non-molecular crystalline phase. When the crystalline phase is decompressed, the amorphous state reappears at $30 \mathrm{GPa}$. We found that on further decompression the first diffraction peak shifted discontinuously between $2.3 \mathrm{GPa}$ and $4.1 \mathrm{GPa}$. On the subsequent compression, the jump in the reverse direction took place at $5.8 \mathrm{GPa}$. These observations suggest the occurrence of structural changes in the amorphous state. We here report a synchrotron x-ray diffraction study of changes in atomic-scale structure of amorphous SnI4.

Diffraction patterns were measured at $2.5 \mathrm{GPa}$ on the first decompression from $29 \mathrm{GPa}$ and at $8.1 \mathrm{GPa}$ and $15 \mathrm{GPa}$ on the second compression. We obtained the Faber-Ziman structure factor $\mathrm{S}(\mathrm{Q})$ at each pressure and the reduced radial distribution function $\mathrm{G}(\mathrm{r})$ by sine transform of $\mathrm{S}(\mathrm{Q})$. In $\mathrm{G}(\mathrm{r})$ at $2.5 \mathrm{GPa}$, peaks corresponding to the intramolecular atomic distance, Sn-I and I-I, were clearly observed. At $8.1 \mathrm{GPa}$ and $15 \mathrm{GPa}$, the Sn-I distance was found to increase and the peak at the I-I distance disappeared, indicating breakup of the SnI4 molecules. These observations lead us to conclude that the pressure-induced structural change in amorphous $\mathrm{SnI}_{4}$ is a phase transition characterized by the molecular dissociation.

Keywords: MOLECULAR CRYSTAL PRESSURE-INDUCED AMORPHIZATION SYNCHROTRON X-RAY DIFFRACTION
Acta Cryst. (2002). A58 (Supplement), C178

CRYSTAL STRUCTURE OF A HIGH-PRESSURE PHASE OF $\mathrm{ZrP}_{2} \mathrm{O}_{7}$ C. T. Prewitt Y. Meng

Carnegie Institution of Washington Geophysical Laboratory 5251 Broad Branch Road, NW WASHINGTON DC 20015 USA

Over the past several years there has been substantial interest in the properties of phases with compositions such as $\mathrm{ZrV}_{2-\mathrm{x}} \mathrm{P}_{\mathrm{x}} \mathrm{O}_{7}$ or $\mathrm{TiV}_{2} \mathrm{O}_{7}$, especially because of their negative thermal expansion (1). Thus, most investigations have been conducted at room pressure with increasing temperature although Carlson and Andersen (2) reported a phase transition in $\mathrm{ZrV}_{2} \mathrm{O}_{7}$ at $1.38-1.58 \mathrm{GPa}$, but no transition in $\mathrm{ZrP}_{2} \mathrm{O}_{7}$ to $40.3 \mathrm{GPa}$ at ambient temperature. However, Sclar et al. (3) had previously reported the synthesis of a high-pressure phase of $\mathrm{ZrP}_{2} \mathrm{O}_{7}$ at pressures up to $10 \mathrm{GPa}$ and $750-1000^{\circ} \mathrm{C}$, so we synthesized a polycrystalline sample of this phase with the composition $\mathrm{ZrP}_{2} \mathrm{O}_{7}\left(\mathrm{ZrP}_{2} \mathrm{O}_{7}\right.$ II) at $7 \mathrm{GPa}$ and $800^{\circ} \mathrm{C}$ in a multi-anvil apparatus. Powder x-ray data were recorded at beamline X7A of the National Synchrotron Light Source. Its unit-cell parameters are $\mathrm{a}=7.538 \AA, \mathrm{c}=7.301 \AA, \mathrm{V}=359.3 \AA 3$, and $\mathrm{Z}=3$. We solved the structure assuming space group $P 31$ and found that it consists of $\mathrm{ZrO}_{6}$ octahedra and $\mathrm{PO}_{4}$ tetrahedra linked in a similar way to the 1 atmosphere structure of $\mathrm{ZrP}_{2} \mathrm{O}_{7} \mathrm{I}$, but with a $17 \%$ higher density. Examination of the structure plus structure refinement indicated additional symmetry elements consistent with space group $P 3121$.

References

(1) Korthuis, V., N. Khosrovani, A.W. Sleight, N. Roberts, R. Dupree, and W.W. Warren, Chem. Mater., 7, 412-417, 1995.

(2) Carlson, S., and A.M.K. Andersen, J. Appl. Cryst., 34, 7-12, 2001.

(3) Sclar, C.B., L.C. Carrison, and C.M. Schwartz, Nature, 204, 573-574, 1964.

Keywords: PHASE TRANSFORMATION ZIRCONIUM PYROPHOSPHATE HIGH PRESSURE 